\title{
Publisher Correction: Direct quantum process tomography via measuring sequential weak values of incompatible observables
}

\author{
Yosep Kim¹, Yong-Su Kim², Sang-Yun Lee (1) ${ }^{2}$, Sang-Wook Han², Sung Moon², \\ Yoon-Ho Kim ${ }^{1} \&$ Young-Wook Cho (1) ${ }^{2}$
}

Correction to: Nature Communications https://doi.org/10.1038/s41467-017-02511-2, published online 15 January 2018

In the original version of this Article, the penultimate sentence of the second paragraph of the "Schematic and theory" section of the Results originally incorrectly read "For instance, choosing $\theta_{\mathrm{A}}=\pi / 4,0,-\pi / 8$ and $\pi / 8$ rotates the bases $|0\rangle,|1\rangle,|+\rangle$, and $|-\rangle$ into $|1\rangle$, thereby implementing the observable $\hat{A}=|0\rangle\langle 0|| 1\rangle,\langle 1||+\rangle,\langle+|$ and, respectively." In the corrected version, " $|-\rangle\langle-|$ " has been added before ", respectively". This error has been corrected in both the PDF and HTML versions of the Article.

Published online: 22 February 2018

\begin{abstract}
(c) Open Access This article is licensed under a Creative Commons Attribution 4.0 International License, which permits use, sharing, adaptation, distribution and reproduction in any medium or format, as long as you give appropriate credit to the original author(s) and the source, provide a link to the Creative Commons license, and indicate if changes were made. The images or other third party material in this article are included in the article's Creative Commons license, unless indicated otherwise in a credit line to the material. If material is not included in the article's Creative Commons license and your intended use is not permitted by statutory regulation or exceeds the permitted use, you will need to obtain permission directly from the copyright holder. To view a copy of this license, visit http://creativecommons.org/licenses/by/4.0/.
\end{abstract}

(c) The Author(s) 2018

\footnotetext{
${ }^{1}$ Department of Physics, Pohang University of Science and Technology (POSTECH), 37673 Pohang, Korea. ${ }^{2}$ Center for Quantum Information, Korea Institute of Science and Technology (KIST), 02792 Seoul, Korea. Correspondence and requests for materials should be addressed to

Y.-H.K. (email: yoonho72@gmail.com) or to Y.-W.C. (email: choyoungwook81@gmail.com)
} 